\title{
Specialist training in Europe: introduction to a special issue of the Journal of Thoracic Disease
}

Specialist training is a critical issue in Europe and worldwide. The trainee is a future colleague from whom we expect that he will deliver the best ever possible quality of care. This best quality of care encompasses a huge number of prerequisites. On the front line appear knowledge and cognitive skills, and psychomotor procedural skills; competence is demonstrated by appropriate decision-making and application of technical skills. During his training, a trainee is expected to progressively escalate the top of the famous Miller's pyramid (1). As opposed to technical skills, which are tested in national or European board examinations, best quality of care requires a broad spectrum of non-technical skills including empathy, team playing, leadership, cost control among other. The Royal College of Physicians of Canada has prepared and published a guideline document called "CanMEDS glossary", which describes 7 fundamentals, yet overlapping areas of competence, centred by medical expertise: communicator, collaborator, leader, health advocate, scholar, and professional (2).

The helicopter view of specialist training in respiratory medicine and surgery over the European space appears as rather chaotic. First of all, the name of specialties and certifying bodies differ from one country to another. Accordingly, the perimeter of the specialty and the content of training are subjected to variations (3). Duration of training and obligation to rotate through neighbour specialties is dissimilar. For surgeons, the recommended operative experience is markedly different (4). As opposed to dissimilar training requirements and pathways, the currently applicable European regulations implicate mutual recognition of specialist diplomas between European Union member states (directive) (5).

The European Respiratory Society recognized this inequity, and started a unique initiative to harmonize training curricula in Europe as early as 2006 (6). After completing a task force on training in Adult Respiratory Medicine, the same methodology based on Delphi consensus has been applied to several subspecialties such as paediatric pulmonary medicine, intensive care, respiratory infections, sleep medicine, physiotherapy (7-11). The 2 most recent task forces have been run in partnership with other European Societies and concern thoracic oncology and thoracic surgery $(2,12)$.

While transfer of knowledge and training cognitive skills is part of traditional teaching, education scientists have demonstrated efficacy of simulation training to acquire technical skills $(13,14)$. Increasing attention is addressed to teaching of non-technical skills; there are different approaches which may be separated in patient centred and team oriented non-technical skills (15). Information technologies have invaded our private lives, and virtual teaching tends to predominate over classic lectures or faceto-face working groups. We will address in this issue the question whether e-learning platforms are the auditorium of the future.

Recognition of procedural skills by a jury requires an inventory of numbers and type of procedures that have been assisted, or performed with help of the mentor. Constitution of a complete and comprehensive portfolio is a critical issue for trainees. The portfolio is not only an assessment tool at the end of training, but should be used as an ongoing monitoring tool allover the training. As such, the portfolio allows both trainee and trainer to check in real time whether already fulfilled training objectives match with the projected curriculum design; in this issue, we present the example of online portfolios designed by French National Society for Thoracic and Cardiovascular Surgery.

New concepts in education science implicate also a reset of evaluation tools and methodology to assess learning outcomes. Among these, the HERMES examination for Respiratory Medicine, and the European Board of Thoracic Surgery certification strive to label a level of competence in a harmonized pan-European approach.

Simulation, e-learning, virtual reality have become part of our world, but cannot completely substitute personal experience. Many training programs encourage mobility of their trainees with fellowships in other institutions in their home country and abroad. Two early career surgeons are reporting about their experience without hiding potential odds.

Outside of training excellent physicians and surgeons, we must think of preparing tomorrow's teachers and leadership. In most countries, scientific degrees and credentials are a prerequisite to embrace an academic career. The different ways of building up a scientific curriculum are discussed in this issue.

Future still offers some challenges. The first challenge is transition from the position of a trainee to autonomous practice. We need to monitor carefully whether the training objectives match with the reality of medical or surgical practice. Besides technical skills, the young graduate discovers other issues such as liability, management of finances and collaborators, networking and other (16). The second, career-long challenge is continuous professional development. Soon after graduation, 
the new-baked specialist is facing natural fading of knowledge. In addition, quickly moving science and technology leads to development of innovative tools for diagnosis and instrumental procedures, new medications, and evolving treatment strategies. Many scientific societies including ESTS and ERS are currently launching strategies for continuous professional development. Besides offering several learning opportunities, the education council of ERS has decided to offer a roadmap in the 8 main disease areas; several working groups are currently working on existing HERMES syllabi in order to adapt them to the needs of continuous professional development in the different disease areas $(17,18)$.

Continuous professional development should lead to accreditation and recertification. However, once again, there are considerable variations between European countries concerning reglementations of life-long learning on the one hand, and recertification on the other hand. However, this additional challenge of the future with a marked political flavour is a matter of professional advocacy rather than education!

We thank all expert authors for their invaluable contribution to this issue. We hope that our common work will be useful to both trainees and trainers!

\section{Acknowledgments}

Funding: None.

\section{Footnote}

Provenance and Peer Review: This article was commissioned by the editorial office, Fournal of Thoracic Disease for the series "Training in Pulmonary Medicine and Surgery". The article did not undergo external peer review.

Conflicts of Interest: Both authors have completed the ICMJE uniform disclosure form (available at http://dx.doi.org/10.21037/ jtd.2019.12.28). The series "Training in Pulmonary Medicine and Surgery" was commissioned by the editorial office without any funding or sponsorship. GM served as the unpaid Guest Editor of the series. DS reports grants from Astra-Zeneca AG, Curetis AG, Boston Scientific, personal fees from Astra-Zeneca AG, Novartis AG, GSK AG, Roche AG, Zambon, Pfizer and Schwabe Pharma AG, Vifor AG, outside the submitted work. The authors have no other conflicts of interest to declare.

Ethical Statement: The authors are accountable for all aspects of the work in ensuring that questions related to the accuracy or integrity of any part of the work are appropriately investigated and resolved.

Open Access Statement: This is an Open Access article distributed in accordance with the Creative Commons AttributionNonCommercial-NoDerivs 4.0 International License (CC BY-NC-ND 4.0), which permits the non-commercial replication and distribution of the article with the strict proviso that no changes or edits are made and the original work is properly cited (including links to both the formal publication through the relevant DOI and the license). See: https://creativecommons.org/licenses/by-nc-nd/4.0/.

\section{References}

1. Miller GE. The assessment of clinical skills/competence/performance. Acad Med 1990;65:S63-7.

2. Royal College of Physicians and Surgeons of Canada. CanMEDS: Better standards, better physicians, better care. Available online: www.royalcollege.ca/rcsite/canmeds/canmeds-framework-e

3. Massard G, Tabin N, Mitchell S, et al. A harmonized European training syllabus for thoracic surgery: report from the ESTSERS task force. Eur J Cardiothorac Surg 2018;54:214-20.

4. Massard G, Tabin N, Mitchell S, et al. A harmonised European training syllabus for thoracic surgery: report from the ESTS/ ERS task force group. Eur Respir J 2018;51:1800370.

5. Directive. 2005/36/EC of the European Parliament and of the Council of 7 September 2005 on the recognition of professional qualifications. Available online: http://eur-lex.europa.eu/legal-content/EN/TXT/?qid=1401715075231\&uri=CELEX\%3A32005L0036

6. Loddenkemper R, Séverin T, Haslam P. European curriculum recommendations for training in adult respiratory medicine: crossing boundaries with HERMES. Eur Respir J 2008;32:538-40. 
7. Gappa M, Noël JL, Séverin T, et al. Paediatric HERMES: a European syllabus in paediatric respiratory medicine. Breathe (Sheff) 2009;5:236-47.

8. De Backer W, Simonds A, Horn V, et al. Sleep HERMES: a European Core Syllabus in respiratory disorders during sleep. Breathe (Sheff) 2011;8:61-8.

9. Artigas A, Pelosi P, Dellweg D et al. Respiratory critical care HERMES syllabus: defining competencies for respiratory doctors. Eur Respir J 2012;39:1294-7.

10. Niculescu A, Noel JL, Aliberti S, et al. Introducing a new HERMES project on respiratory infections. Breathe (Sheff) 2016;12:5-7.

11. Troosters T, Tabin N, Langer D, et al. Introduction of the harmonised respiratory physiotherapy curriculum. Breathe (Sheff) 2019;15:110-5.

12. Gamarra F, Noel JL, Brunelli A, et al. Thoracic oncology HERMES: European curriculum recommendations for training in thoracic oncology. Breathe (Sheff) 2016;12:249-55.

13. Nashaat A, Sidhu HS, Yatham S, et al. Simulation training for lobectomy: a review of current literature and future directions. Eur J Cardiothorac Surg 2019;55:386-94.

14. Pietersen PI, Madsen KR, Graumann O, et al. Lung ultrasound training: a systematic review of published literature in clinical ultrasound training. Crit Ultrasound J 2018;10:23.

15. Gjerra K, Mundt AS, Spanager L, et al. Important non-technical skills in video-assisted thoracoscopic surgery lobectomy: team perspectives. Ann Thorac Surg 2017;104:329-35.

16. Kraev A, Merrit-Genore HM. Hello from the other side: what I wish I'd done differently in training. J Thorac Cardiovasc Surg 2017;153:1434-6.

17. Mitchell S, Riha RL, Rohde G, et al. Continuing professional development: introducing the ERS international certificate in sleep medicine. Breathe (Sheff) 2017;13:11-4.

18. Farr A, Gaga M, Welte T, et al. The European Respiratory Society: ensuring excellence through education best practice. Eur Respir J 2018;52:1801248.

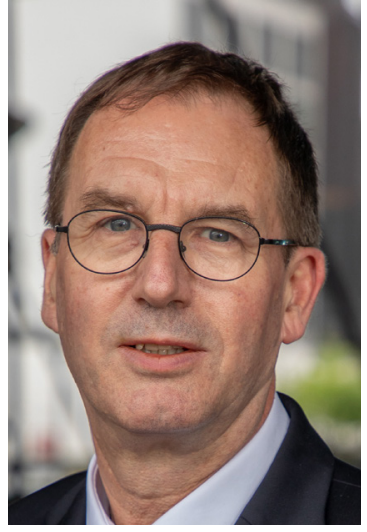

Gilbert Massard

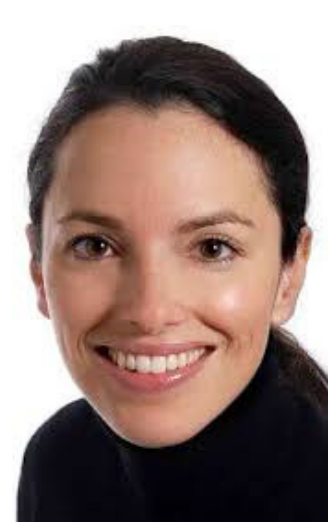

Daiana Stolz
Cite this article as: Massard G, Stolz D. Specialist training in Europe: introduction to a special issue of the fournal of Thoracic Disease. J Thorac Dis 2021;13(3):2018-2020. doi: 10.21037/ jtd.2019.12.28 